\title{
I4. I Clinical spectrum and outcome in 100 children with positive antiphospholipid antibodies
}

\author{
M Rozic*1, A Trampus-Bakija1 ${ }^{1}$, Z Rener-Primec ${ }^{1}$, L Kitanovski ${ }^{1}$, T Kveder ${ }^{2}$ and \\ T Avcin 1
}

Address: ${ }^{1}$ University Children's Hospital, University Medical Center Ljubljana, Ljubljana, Slovenia and ${ }^{2}$ Department of Rheumatology, University Medical Center Ljubljana, Ljubljana, Slovenia

* Corresponding author

from 15th Paediatric Rheumatology European Society (PreS) Congress

London, UK. 14-17 September 2008

Published: 15 September 2008

Pediatric Rheumatology 2008, 6(SuppI I):S28 doi:10.1 I86/I546-0096-6-SI-S28

This abstract is available from: http://www.ped-rheum.com/content/6/SI/S28

(c) 2008 Rozic et al; licensee BioMed Central Ltd.

\section{Objective}

To evaluate the prevalence of thrombotic and non-thrombotic clinical manifestations and long-term outcome in a large group of children with positive antiphospholipid antibodies (aPL).

\section{Methods}

We retrospectively reviewed medical records from January 1997 to November 2007 at University Children's Hospital Ljubljana for all patients who tested positive for aPL. Testing for aPL was requested by the treating physician given the clinical suspicion of aPL-related manifestations. All patients fulfilled the consensus laboratory criteria for antiphospholipid syndrome.

\section{Results}

We identified 190 aPL-positive patients and randomly selected 100 patients for detailed evaluation. Sixty-two were girls and 38 boys with mean age at presentation 9.7 years. Twenty-seven (27\%) patients had underlying systemic autoimmune disease (SLE 16, JIA 8). Sixty patients presented with one, 14 with two and 13 with three or more aPL-related clinical manifestations. Thromboses occurred in $10(10 \%)$ patients and one patient had recurrent thrombosis. One or more non-thrombotic clinical manifestations were found in 77 (77\%) patients including hematological disorders in 27 (thrombocytopenia 20, autoimmune hemolytic anemia 2), neurological disorders in 26 (migraine 15, seizures 3, chorea 2) and skin disor- ders in 22 patients (livedo reticularis 9, Raynaud's phenomenon 4). Seventeen infants born to mothers with aPL-positive autoimmune disease had positive aPL and 4 of them exhibited aPL-related clinical manifestations.

\section{Conclusion}

In our cohort, thrombotic events occurred only in $10 \%$ of all symptomatic patients with positive aPL evaluated at the tertiary care pediatric hospital. The most common non-thrombotic manifestations found in children with aPL were thrombocytopenia, migraine headache and livedo reticularis. 